\title{
Prevalence of Worm Infection in Relation to Body Mass Index in Children of 5-10 Yrs of Age in Tehsil Narowal, Pakistan
}

\author{
Muhammad Abdul Shakoor, ${ }^{1, *}$, Imtiaz Ahmad Khan ${ }^{2}$, Hajira Ahmed ${ }^{1}$, Mahpara Safdar ${ }^{1}$, \\ Zaheer Ahmed ${ }^{1}$, Asma Afreen ${ }^{1}$ \\ ${ }^{1}$ Department of Home and Health Sciences, Allama Iqbal Open University, Islamabad, Pakistan \\ ${ }^{2}$ Department of Pathobiology, PMAS Arid Agriculture University, Rawalpindi, Pakistan
}

Copyright $(\mathrm{C} 2018$ by authors, all rights reserved. Authors agree that this article remains permanently open access under the terms of the Creative Commons Attribution License 4.0 International License

\begin{abstract}
Aim: To assess the magnitude of worm infections, their type and to correlate the impact of worm infections in children with their body mass index. Method: The study was carried out on school going children for 5-10 years of age in Tehsil Narowal, District Narowal, and Pakistan. They were of different age groups with lower socio economic status. 406 children randomly selected from various government and private schools from the various union councils for both genders (male and female). Early morning fresh stool samples were collected in sealed labeled plastic containers with lid and analyzed microscopy for the presence of eggs/ova/larvae or worm infections in laboratory. Anthropometric measurements were taken at the spot by using measuring scale for weight and height along with their mid arm circumferences. Body Mass Index was calculated and compared with standard percentile charts for age and gender. Results: 145 (35.71\%) children found with various types of worm infection. 56 (35.67\%) and $89(35.74 \%)$ children were positive with helminthes male and female respectively in the studied population. Sixth and seventh year of age in both male and female were more susceptible for the infestation. Taenia saginata was the more common found organism in gastrointestinal tract of male population and Giardia lamblia in female among the children of studied area. 137 (94.48\%) children were infected with the single intestinal worm while only $8(5.52 \%)$ children with more than one intestinal worm. $57.24 \%$ had lower, $41.4 \%$ had normal and only $1.4 \%$ had above normal BMI among infected children. Majority (65.9\%) had normal, 27.2\% had lower than normal, and $6.9 \%$ had above normal BMI found among non-infected children. Conclusion: From the results of present study it can be concluded that intestinal worms play significant role in reducing anthropometric measurement of school going children. The factors including personal hygiene, dietary habits, type of drinking water, animals and
\end{abstract}

pets keeping, overcrowded and congested living environment, large family members, toilet facility, toilet trainings, personal hygiene awareness, PICA habits and lack of de-worming contributes largely towards the worm burden in the children. A single cause is not only the attributing factor to reduce the anthropometric measurements.

Keywords Worm Infections, Anthropometric, Body Mass Index

\section{What is Already Known on This Topic}

1. Worm infections play important role in health deterioration.

2. Despite of improved socioeconomic conditions and elevated living standards still it is public health problem.

3. It is major childhood health problems in developing countries.

4. Soil transmitting helminthes (Ascaris Lumbricoides, hookworm and Trichuris trichiura) are the most prevalent and infecting approximate one third of the global population.

\section{What This Paper Adds}

1. Study provides the evidences of relationship in between worm infection and health deterioration.

2. More than $50 \%$, infected children presented with their lower body mass index during the anthropometric measurements

3. Taenia saginata and Giardia lamblia was the most prevalent organism found in the children caused by unsafe drinking water and un/half cooked food. 
4. Sixth and seventh years of age groups were found more susceptible for the worm infections.

Few years back there was a growing interest to identify the role of intestinal worm infection with their Body Mass Index and it was revealed that these infections plays their important role in children for their physical and mental development. These infections refer to worm that live as parasites in the human. Globally, it was estimated that about 5.3 billion of population were at risk for the worm infections including 1 billion school age children. $69 \%$ of risk population lives in the Asia [1].

Soil transmitted helminthes are due to their presence in the human soil and majority of the individuals infected in the areas where the sanitation is poor. The most common organism found in the intestine is Ascaris lumbricoides, Trichuris trichiura, Ancylostoma duodenale. These parasitic infections may lead to anemia, vitamin A deficiency, stunted growth, malnutrition, intestinal obstruction and impaired development [2].

School going children are particularly at great risk for getting parasitic infections. The parasitic roundworms consume nutrients from the gut of patients, which lead to malnutrition and growth problems. Children caught worm infection when living in unclean environment with poor sanitation with poor education about the worm infections. The proper education is only possible when they will be physically and mentally healthy. Worm infection play very important role in terms of health deterioration because of various reasons, may be due to contaminated food and water with worm's larvae and eggs (Ascaris lumbricoides and Trichuris trichiura), or through active penetration of the skin by infective larval stages present in contaminated soil hookworm [3].

The current study was conducted to investigate the magnitude of worm infections in children of middle childhood and to find its impact on their body mass index (BMI). After verbal consent from parents, 406 children of both genders between the ages of 5-10 years were selected from both urban and rural areas of Tehsil Narowal, Pakistan. Stool samples were collected in labeled plastic containers with lid and analyzed microscopically for parasites, if any, and their types. Anthropometric measures including weight and height were taken by using standard tools. The results indicated that out of total, $35.71 \%$ were infected with worms of different categories for different age groups. There were 157 male and 249 female children. Intestinal worm infections were diagnosed in $35.67 \%$ male and $35.74 \%$ female children. Taenia Saginata was the most common specie $(33.79 \%)$ and the $H$. nana was the least common organism (4.82\%). Majority (94.48\%) children were infected with single and a few (5.52\%) with more than one intestinal worm. The common infected age group was 6-7 years for both genders. Taenia Saginata was the most prevalent organism in male and Giardia in female, during these years. Cestode was the most frequent $(35.86 \%)$ intestinal worm. Among infected children,
$37.93 \%$ were having animals/pets at their household level. It was also identified that $42.39 \%$ children were using tap water for drinking. Among infected children, 57.24\% had lower, $41.4 \%$ had normal and only $1.4 \%$ had above normal BMI. Among non-infected children, majority (65.9\%) had normal, $27.2 \%$ had lower than normal, and $6.9 \%$ had above normal BMI. It is concluded that more than $1 / 3^{\text {rd }}$ of children were infected with a variety of intestinal worms in both urban and rural areas. Taenia Saginata and Giardia were the most prevalent organisms found at the age of 6-7 years. Presence of intestinal worms in the children affects their nutritional uptakes from the intestine and hence their nutritional status, growth and development. It is therefore suggested that awareness programs about the importance of health during these growing years, personal hygiene, use of safe drinking water and pets keeping training so that to reduce the burden of disease and prevailing under nutrition.

\section{Methods}

\section{Sample and Procedures}

Data for the current study was collected from the different government and private schools from different union councils of Tehsil Narowal, Pakistan. Only 5-10 years of age was selected to identify the burden of disease and its impact on their health. Majority of the children belongs to the lower socio economic status and experienced house hold poverty. Participating children were slightly more likely to be female than male. It was a cross sectional observational study. The approximate sample size was required to estimate the prevalence in large population which can be determined for a defined precision and level of confidence [4].

The formula used for the sample size calculation for a $95 \%$ confidence interval is as below;

Sample size:

Formula:

$$
n=\frac{1.96 \times 1.96 \times P \exp .(1-P \exp .)}{d \times d}
$$

where:

$\mathrm{n}=$ required sample size, $\mathrm{P} \exp =$ expected prevalence, $\mathrm{d}=$ desired absolute precision $50 \%$ is to be estimated with desired absolute precision of $5 \%$ (i.e. the limit of the associated $95 \%$ interval are $25 \%$ and $35 \%$ ) then, $\mathrm{P}$ exp = 0.50 and $\mathrm{d}=0.05$

Substituting these values in the formula:

Sample size: Formula:

$$
\begin{gathered}
n=\frac{1.96 \times 1.96 \times 0.50(1-0.50)}{0.50 \times 0.50} \\
n=384.16(\text { Children })
\end{gathered}
$$


So; according to the formula the absolute sample size was 384 children to ascertain the prevalence of various kinds of worm and its epidemiological attributes [5].

Anthropometric data was collected by measuring the weight and height along with calculation of body mass index (BMI). The exercise was carried by the scholar along with trained school teachers team constituted on the spot. Early morning stool samples were collected from 406 school children including government and private schools during the period of January 2016 and May 2016 in labeled plastic containers with lids. Second stool sample were collected for the children with negative first stool sample microscopically.

Stool samples were subjected to microscopic examination for the presence of variety of worms identified through the eggs/ova/larvae in well established diagnostic laboratory by qualified staff. A questionnaire was developed to collect the socio economic status including name, age, gender, family members, presence of animals and residential area etc. and specific data for a family and child taken which includes source of water, availability of toilet facility and training of child, personal hygiene, PICA habits along with the history of presence of worms and its de-worming. The Body Mass Index in relation to the age was calculated according to the WHO standard formula and the results plotted on the WHO standard BMI for age percentiles charts to assess the nutritional status, separately for male and females

Formula:

BMI: weight $(\mathrm{Kg}) /[\text { Height }(\mathrm{m})]^{2}$

With the metric system, the formula for BMI is weight in kilograms divided by the height in meters squared.

School principals were agreed for the participation of their schools. Study information was shared with the parents during the parent's teachers meeting days before the exercise to be done including stool sample collection, socioeconomic status and specific data of the child and family and anthropometric measurements. Responses from the each respondent and anthropometric measurement were recorded in written on the developed questionnaire. Well being of the family and Socioeconomic status was identified with the help self established questionnaire which includes parents education, source of income, number of children, total family members, presence and types of animals / pets, residential area, approximate family monthly income in rupees as ascribed by Agarwal et al. 2005 , source of water along with availability of toilet facilities at house hold level.

Microscope, Clinical Centrifuge Machine, $0.9 \%$ Normal Saline, Glass Test tubes, Glass slide, Glass Cover slips were used in well established laboratory for the microscopic analysis of collected stool samples.

Inclusion or exclusion criteria were specific to the children of 5-10 years of age (including both 5 and 10 years) along with residents of Tehsil Narowal, Pakistan. The children out of 10 and 5 years of age and having their residence out of Tehsil Narowal were not included in the study.

\section{Statistical Analysis}

The data thus obtained in study were subjected to statistical analysis using statistical software SAS 6.12 on personal computer for the calculation of Chi Square values [6].

Various attributing factors which may associate with intestinal worm infections were analyzed. Associations were considered statistically significant at $P$ Value $\leq 0.05$.

The prevalence of worm infection in children of 5-10 years of age found more than $1 / 3^{\text {rd }}$. It was found that female children were more prone to infect with intestinal worms i.e. $35.74 \%$ as compared to male children i.e. $35.67 \%$.

Table 1. Severity of Worm Infections in Sequence among Children

\begin{tabular}{|c|c|c|}
\hline Type of worm & No. Of infested & Percentage \\
\hline Taenia Saginata & 49 & 33.79 \\
\hline Giardia & 42 & 28.96 \\
\hline Enterobius Vermicularis & 33 & 22.75 \\
\hline Hook Worm & 11 & 7.58 \\
\hline Parasitic Eggs & 11 & 7.58 \\
\hline Mixed Infection & 8 & 5.51 \\
\hline H. nana & 7 & 4.82 \\
\hline
\end{tabular}

Severity of identified worm infections in both male and females examined children explained in the above table. Taenia saginata was found most prevalent organism i.e. $33.79 \%$ from all 145 infected children. H. nana is the least found identified organism among infected children i.e. $4.82 \%$. Large number of children was infected with single worm and very few were with mixed type of intestinal infection observed.

Table 2. Type of Infections among Infected Children

\begin{tabular}{|c|c|c|}
\hline \multirow{2}{*}{ Types of worm } & \multicolumn{2}{|c|}{ Infected children } \\
\cline { 2 - 3 } & Number & Percentage \\
\hline Nematodes (Single Worm) & 37 & 25.52 \\
\hline Cestodes (Single Worm) & 52 & 35.86 \\
\hline Trematodes (Single Worm) & 0 & 0 \\
\hline Parasitic Eggs (Unicellular) & 11 & 7.59 \\
\hline Mixed Infestation & 7 & 4.83 \\
\hline Protozoa & 38 & 26.20 \\
\hline & 145 & 100 \\
\hline
\end{tabular}

Different types of intestinal worms were identified including nematodes (Enterobius vermicularis, Hookworms), cestodes (Taenia saginata, H. nana) through stool microscopy of children in 5-10 years of age. The most prevalent organism in stool was cestodes comprise of Taenia saginata and H. nana i.e. 35.86\% (52/145). No Trematodes was found in all the examined stool of children 
in Tehsil Narowal.

Table 3. Distribution of Data According to Source of Water and Infections

\begin{tabular}{|c|c|c|c|c|}
\hline $\begin{array}{c}\text { Source of } \\
\text { water }\end{array}$ & $\begin{array}{c}\text { No. Of } \\
\text { selected } \\
\text { children }\end{array}$ & $\begin{array}{c}\text { Worm } \\
\text { infected } \\
\text { children }\end{array}$ & Percentage & $\begin{array}{c}\text { Chi square } \\
\text { value }\left(\mathrm{x}^{2}\right)\end{array}$ \\
\hline Deep bore & 298 & 100 & 33.55 & \multirow{2}{*}{2.41} \\
\cline { 1 - 4 } Tap water & 92 & 39 & 42.39 & \multirow{2}{*}{0.29} \\
\cline { 1 - 3 } $\begin{array}{c}\text { Others } \\
\text { Nalka etc) }\end{array}$ & 16 & 6 & 37.5 & \\
\cline { 1 - 3 } P Value & \multicolumn{3}{|c|}{0.29} \\
\hline
\end{tabular}

Children using tap water for drinking were $42.39 \%$ (39/92) infected with worms along with $33.55 \%$ (100/298) of deep bore usage. The most infected percentage i.e. $37.5 \%(6 / 16)$ was of those using other source of water like Nalka, for their drinking or other activities. The P Value showed that there is nothing significant in the above table for the intestinal worm infections in children.

Table 4. Distribution of Data According to Toilet Training of Child and Infections

\begin{tabular}{|c|c|c|c|c|}
\hline $\begin{array}{c}\text { Toilet } \\
\text { habits }\end{array}$ & $\begin{array}{c}\text { Selected } \\
\text { children }\end{array}$ & $\begin{array}{c}\text { Worm } \\
\text { infected } \\
\text { children }\end{array}$ & Percentage & $\begin{array}{c}\text { Chi square } \\
\text { value }\left(\mathrm{x}^{2}\right)\end{array}$ \\
\hline $\begin{array}{c}\text { Washing } \\
\text { himself }\end{array}$ & 377 & 132 & 35.01 & \multirow{2}{*}{1.22} \\
\cline { 1 - 3 } $\begin{array}{c}\text { Mothers } \\
\text { help }\end{array}$ & 12 & 5 & 41.66 & \\
\cline { 1 - 3 } $\begin{array}{c}\text { No } \\
\text { regular } \\
\text { habit }\end{array}$ & 17 & 8 & 47.05 & \\
\hline P Value & \multicolumn{3}{|c|}{0.54} \\
\hline
\end{tabular}

Children not having the regular habit to wash after the toilet were of $47.05 \%(8 / 17) .41 .66 \%(5 / 12)$ were those of with mother help. 35.01\% (132/377) infected with the habit of washing himself after the toilet usage. As the level of significance $P$ Value is less than or equivalent to $\leq 0.05$ and the calculated P Value was 0.544 so the only toilet training of child was not significant for the intestinal worm infections.

Table 5. Distribution of Data According to Pica Habits and Infections

\begin{tabular}{|c|c|c|c|c|}
\hline \multirow{2}{*}{ Habits } & \multirow{2}{*}{$\begin{array}{c}\text { No. Of selected } \\
\text { children }\end{array}$} & \multicolumn{2}{|c|}{ Infected children } & $\begin{array}{c}\text { Chi square } \\
\text { value }\left(\mathrm{x}^{2}\right)\end{array}$ \\
\cline { 3 - 4 } & & Number & Percentage & \multirow{2}{*}{1.42} \\
\hline PICA & 65 & 19 & 29.23 & \\
\hline $\begin{array}{c}\text { No } \\
\text { PICA }\end{array}$ & 341 & 126 & 36.95 & \\
\hline P Value & \multicolumn{4}{|c|}{0.23} \\
\hline
\end{tabular}

Children do not have the history of PICA in their routine they were calculated $36.95 \%$ (126/341) and only $29.23 \%$ $(19 / 65)$ infected children with PICA habits identified through stool microscopy and with the help of formulated questionnaire. P-Value in the analysis was 0.234 which shows nothing significant whether the children have or have not PICA habits for the intestinal worm infections.

Table 6. Association of Worm Infections with Personal Hygiene Practices

\begin{tabular}{|c|c|c|c|c|}
\hline \multirow{2}{*}{$\begin{array}{c}\text { Hygiene \& } \\
\text { practice activity }\end{array}$} & \multirow{2}{*}{$\begin{array}{c}\text { Selected } \\
\text { children }\end{array}$} & \multicolumn{2}{|c|}{ Infected children } & \multirow{2}{*}{$\begin{array}{c}\text { Chi square } \\
\text { value }\left(\mathrm{x}^{2}\right)\end{array}$} \\
\cline { 1 - 4 } $\begin{array}{c}\text { Washing hands } \\
\text { before meal }\end{array}$ & 256 & 84 & 32.81 & \\
\hline $\begin{array}{c}\text { Do not wash } \\
\text { hands before } \\
\text { meal }\end{array}$ & 150 & 61 & 40.66 & \\
\hline $\begin{array}{c}\text { Washing hands } \\
\text { after meal }\end{array}$ & 59 & 18 & 30.50 & \multirow{2}{*}{4.12} \\
\hline $\begin{array}{c}\text { Do not wash } \\
\text { hands after } \\
\text { meal }\end{array}$ & 347 & 127 & 36.59 & \multirow{2}{*}{ Percentage } \\
\hline $\begin{array}{c}\text { Washing hands } \\
\text { after toilet }\end{array}$ & 259 & 93 & 35.90 & \\
\hline $\begin{array}{c}\text { Do not wash } \\
\text { hands after } \\
\text { toilet }\end{array}$ & 147 & 52 & 35.37 & \\
\hline P Value & & \multicolumn{2}{|c|}{0.53} \\
\hline
\end{tabular}

The children washing their hands before meal were infected $32.81 \%(84 / 256)$ according to the survey on prescribed questionnaire. $40.66 \% \quad(61 / 150)$ infected children with do not wash hands before meal. $35.37 \%$ (52/147) infected children with habit of do not wash hands after toilet, along with the infected children of habit of washing hands after toilet i.e. $35.9 \%(93 / 259)$. The P-value for the analysis of personal hygiene was 0.532 which is more than 0.05 and it was not significant so these issues were not only the factor for intestinal worm infections in children.

Table 7. Distribution of Data According to the BMI Status in Children

\begin{tabular}{|c|c|c|c|}
\hline $\begin{array}{c}\text { BMI } \\
\text { status }\end{array}$ & $\begin{array}{c}\text { Infected children } \\
\text { (Total 145) }\end{array}$ & $\begin{array}{c}\text { Non-infected } \\
\text { children }(261)\end{array}$ & $\begin{array}{c}\text { Chi-square } \\
\text { value }\left(\mathrm{x}^{2}\right)\end{array}$ \\
\hline Low BMI & 83 & 71 & \multirow{2}{*}{37.74} \\
\cline { 1 - 3 } $\begin{array}{c}\text { Normal } \\
\text { BMI }\end{array}$ & 60 & 172 & \\
\hline $\begin{array}{c}\text { Over } \\
\text { BMI }\end{array}$ & 02 & 18 & \\
\hline P - value & \multicolumn{3}{|c|}{0.00} \\
\hline
\end{tabular}

Table 9 described the BMI status for all the study population. A large proportion of worm infected children $83 / 145(57.2 \%)$ were with significantly $<0.05$ lower body mass index followed by the worm infected children with no effect on body mass index 60/145 (41.4\%) and with higher body mass index $2 / 145(1.4 \%)$ respectively. The above table also describes the body mass index status for the non-infected children with worms. A significant number of children 71/261 (27.20\%) were identified with their lower body mass index in the selected area during the period of study.

\section{Discussion}


Worm infection in school going children is one of the major health constraints inflicting low optimum performance in the form of body mass index, mental health and lower immunity. It drastically reduces the learning ability of children. In the country like Pakistan the existing socio-economic issues seriously affects the aforementioned heath parameters in school going children. Worm infection is being picked from the surrounding of the host (children) particularly in the school going groups where eating and watering are shared. There are other accidental ways of getting infection and often mistakenly by physical contact with dirty hands, touching infected animal (farm animals and pets). Parasitic eggs are passed in stool/faeces after laying in the gastrointestinal tract can pass out of the body and contaminate the surroundings which is shared by the infected and non-infected individuals. Pet/animal health is another unaddressed aspect of this kind of infection which is being increased because of poor knowledge about the animal keeping and diseases which are zoonotic in nature particularly the worm infection. So regular monitoring of animal health is missing which contribute the lion share in different ways. Family share the infection because of common living and eating together with the infected individuals and pets in various ways.

The present study was conducted to ascertain the magnitude of worm infection in school going children of various age groups and belongings of different socioeconomic status. Stool microscopy of 406 children of both genders (Male $=157$ and Female $=249$ ) in private and government schools was carried to elucidate the infected and non-infected children. Epidemiological data was acquired on a preformed proforma by interviewing the individual cases along with anthropometric measurements according to WHO criteria.

A total of 145 children of both genders (Male $=56$ and Female=89) were found positive for the worm infection through stool microscopy. Six and seven years of age groups were found more infected with worms. The male respondents in the study were largely infected with Taenia saginata $(37.5 \%)$ while female respondents were infected with Giardia lamblia (27\%).

Taenia saginatais a cestode known to be a beef tapeworm was significantly found higher proportions in male children in the study area. The mode of infection is acquired through raw or poorly cooked meat from infected animals. Animals may get infected while grazing and drinking contaminated water with parasite eggs and larvae. They get penetrated through animal intestinal wall and remain in the flesh [7]. Males have more vital role than females in communities with rural background and lower socio economic status for the future prospective so, the male children are trying to be better fed with high protein diets.

Evidences to support the zoonotic transmission of Giardia are very supportive with children with animals and pets at their homes. The greatest risk of zoonotic transmission appears to be from companion animals such as dogs and cats [8]. A significant percentage of Giardia infection in female children was found in rural areas of study population and it was ascertained that it is considerable waterborne pathogen. The female children spend more time at house and interact longer with pets and were more involved in animal keeping activities such as to provide feed and water to the domestic animals at their household level which in turn may lead to more susceptibility for the Giardia lamblia infection. Rural areas were found to be more infected with worms as compared to urban areas under study.

Drinking water is a major source of infections in the developing countries, other than poor sanitation and food sources. Complications of the gastrointestinal diseases are more severe due to the under nutrition and lack of interventional strategies in the developing countries. Poor quality of water, sanitation and hygiene accounts for some 1.7 million deaths a year worldwide. Nine out of ten deaths in the children occurred in the developing countries [9]. Among different epidemiology attributes the unsafe tap water for drinking was one of the outstanding feature shared $42.39 \%$ infected individuals in the study areas. Deep bore water usage also contributed a significant percentage $(33.55 \%)$ of worm infection in the stool microscopy in the study area and it is considered that this was only because of post collection practices adopted by the families. Their personal hygiene, cleanliness of the utensils used for the collection and storage, irregular disinfecting of water storing tanks along with shared meal and drinking practices might be the contributing factors for this finding.

Personal hygiene related issues accounts a large number of individuals infected with the intestinal worm infections in children. Ascaris lumbricoides is one of the major parasite found in the community having poor sanitation practices in their routine life [10]. The children with the habits of not washing hands before meal revealed $40.66 \%$ positive for worm infections in the study area. More than $35 \%$ children were those do not have the habit to practice to wash their hands after the toilet usage, in school going age.

PICA habit was observed most commonly in the areas of low socio-economic status and more common in women (pregnant) and in children. Various complications of the disorder have been reported before including iron deficiency anemia, lead poisoning and helminthes infections. PICA is the behavioral pattern driven the multiple factors [11]. Study was conducted in children of specific age groups from 5-10 years only. It revealed that the PICA habit contributed a large proportion of intestinal worm infections in children and causing the poor performance not only in their motor activities but mental deterioration as well.

Health of school going children grossly effected by the presence of intestinal worm infection. Absenteeism and poor school performance markedly reduced after 
de-worming by one quarter [12]. Hookworm infection study was carried out in Ghana where number of households visited and 292 subjects were isolated for the purpose. The overall prevalence of hookworm was $45 \%$. The data confirms high prevalence of low intensity hook worm infections and its association with poor nutritional status [13]. Intestinal parasitic infections often associated with the iron deficiency anemia, malnutrition, Vit. A deficiency along with other complications. Poor nutritional status and functional impairment including decreased physical fitness and decreased work capacity are associated with worm infections in study conducted during 1970s and 1980s [14]. Overall a larger proportion of studied population of school going children was significantly $(\leq$ 0.05 ) infected with worms in the study area. This revealed significant effect on BMI (body mass index) which ultimately reduces the performance of individuals with all respects including their physical and mental activities. Among infected children, 57.24\% had lower, $41.4 \%$ had normal and only $1.4 \%$ had above normal BMI. Presence of worm infections markedly reduces the body mass index experiential in the study area of Tehsil Narowal. Among non-infected children, majority $(65.9 \%)$ had normal, $27.2 \%$ had lower than normal, and $6.9 \%$ had above normal BMI respectively.

In a study it has been reported that worm infections affect the growth of children and this was not consistent. The treatment with single or mixed anthelminthic drug has not significant effect on the weight gain. There were insufficient evidences to improve the cognitive performance of a child even after de-worming during the study trials [15]. Worm infections effect the growth of a child in terms of weight and height. Stunted growth observed in the school going children which is shown in the Body Mass Index of WHO standard percentile charts in the study area. More than $50 \%$ infected children presented with the lower body mass index during their anthropometric measurements.

Childhood stunting is the major and one of the most significant impediments in the child development. Approximate 162 million children affected globally under the age of 5 years. Stunting, for one's age is defined as the height that is more than two standards deviations below the World Health Organization child growth standards median. It is largely irreversible outcome of the malnutrition and repeated infections. Stunting has long term impacts on the societies including the diminished physical and cognitive development which ultimately leads to the poor productive capacity and health along with the degenerative changes e.g. diabetes in later stages. If the current trends continue, the large number of children approximately 127 million will be observed with the stunted growth in the year 2025 . So, further investment and interventions will be required to achieve the WHO targets for the purpose [16]. More than one third children were infected with the intestinal worms from the targeted population and more than $57 \%$ infected children observed with the lower body mass index according to the WHO standards. Interventions in terms of anthelminthic drugs and health education will be required to combat against the disease burden, to achieve the WHO targets in the study area too. Identified worm infected children were shared with teachers at the spot and with parents during their parent teachers' meetings.

\section{Conclusions}

From the results of present study it can be concluded that intestinal worms play significant role in reducing anthropometric measurement of school going children. The factors including personal hygiene, dietary habits, type of drinking water, animals and pets keeping, overcrowded and congested living.

\section{Acknowledgements}

I am thankful to my supervisor Dr. Imtiaz Ahmad Khan, Associate Professor, Department of Patho-biology, Pir Mehr Ali Shah Arid Agriculture University, and Rawalpindi. Special thanks to the respected faculty members of Home and Health Sciences department, Allama Iqbal Open University, Islamabad including Dr. Hajira Ahmed, Dr. Mahpara Safdar, Dr. Zaheer Ahmed and miss Asma Afreen for their kind gaudiness and support at all the levels and whenever needed with utmost dedication to complete the research work throughout the period of study and thesis writing.

I extend my thanks to my elder Mr. Muhammad Abdul Quddus, Dr. Muhammad Aqeel, Mr. Muhammad Asad Iqbal Khan and Mr. Rana Abdul Basit who provided help whenever and wherever required accomplishing this meager effort.

This acknowledge will be incomplete without mentioning the respectable Principal and teachers, Muhammad Aqeel, Sadaf Zahid, Nazia, Muhammad Zahid, Dr. Mohsin. Their memorable company and moral encouragement in every stage in the study has been very vital for me.

\section{REFERENCES}

[1] Pullan RL, Brooker SJ. The global limits and population at risk of soil-transmitted helminth infections in 2010. Parasites \& vectors. 2012; 5(1):81.

[2] Organization WH. Sustaining the drive to overcome the global impact of neglected tropical diseases: second WHO report on neglected tropical diseases: summary. 2013.

[3] Shah SA, Zai S, Muhammad A. Correlation of haemoglobin level with intestinal parasites in school children. Journal of Postgraduate Medical Institute (Peshawar-Pakistan). 2011; 
20(3).

[4] Thrusfield M. Diagnostic testing. Veterinary epidemiology. 1995; 2: 266-85.

[5] Kasiulevičius V, Šapoka V, Filipavičiūtẻ R. Sample size calculation in epidemiological studies. Gerontologija. 2006; 7(4):225-31.

[6] Littell RC. SAS: Wiley Online Library; 1996.

[7] Dorny P, Praet N. Taenia saginata in Europe. Veterinary Parasitology. 2007; 149(1):22-4.

[8] Thompson RA. The zoonotic significance and molecular epidemiology of Giardia and giardiasis. Veterinary parasitology. 2004; 126(1):15-35.

[9] Ashbolt NJ. Microbial contamination of drinking water and disease outcomes in developing regions. Toxicology. 2004;198(1): 229-38.

[10] Mengistu A, Gebre-Selassie S, Kassa T. Prevalence of intestinal parasitic infections among urban dwellers in southwest Ethiopia. Ethiopian Journal of Health Development. 2007; 21(1):12-7.

[11] Rose EA, Porcerelli JH, Neale AV. Pica: common but commonly missed. The Journal of the American Board of
Family Practice. 2000; 13(5):353-8.

[12] Miguel E, Kremer M. Worms: identifying impacts on education and health in the presence of treatment externalities. Econometrica. 2004; 72(1):159-217.

[13] Humphries D, Mosites E, Otchere J, Twum WA, Woo L, Jones-Sanpei H, et al. Epidemiology of hookworm infection in Kintampo North Municipality, Ghana: patterns of malaria coinfection, anemia, and albendazole treatment failure. The American journal of tropical medicine and hygiene. 2011; 84(5):792-800.

[14] Gilgen D, Mascie - Taylor C, Rosetta L. Intestinal helminth infections, anaemia and labour productivity of female tea pluckers in Bangladesh. Tropical medicine \& international health. 2001; 6(6):449-57.

[15] Dickson R, Awasthi S, Williamson P, Demellweek C, Garner P. Effects of treatment for intestinal helminth infection on growth and cognitive performance in children: systematic review of randomised trials. Bmj. 2000; 320(7251):1697-701.

[16] Organization WH. Global nutrition targets 2025: Stunting policy brief. 2014. 